\title{
Affordable Development of a Nuclear Cryogenic Propulsion Stage
}

\author{
M. G. Houts ${ }^{1}$, S. K. Borowski ${ }^{2}$, J. A. George ${ }^{3}$, T. Kim ${ }^{1}$, W. J. Emrich ${ }^{1}$, R. R. Hickman ${ }^{1}$, J. W. \\ Broadway $^{1}$, H. P. Gerrish ${ }^{1}$, R. B. Adams ${ }^{1}$. ${ }^{1}$ NASA Marshall Space Flight Center, MSFC, AL \\ 35812, ${ }^{2}$ NASA Glenn Research Center, Cleveland, OH, 44135, ${ }^{3}$ NASA Johnson Space Center, \\ Houston, TX, 77058
}

\section{$\underline{\text { Overview }}$}

The fundamental capability of Nuclear Thermal Propulsion (NTP) is game changing for space exploration. A first generation Nuclear Cryogenic Propulsion Stage (NCPS) based on NTP could provide high thrust at a specific impulse above $900 \mathrm{~s}$, roughly double that of state of the art chemical engines. The foundation provided by development and utilization of a NCPS could enable development of extremely high performance systems. The role of the NCPS in the development of advanced nuclear propulsion systems could be analogous to the role of the DC-3 in the development of advanced aviation. Progress made under the NCPS project could help enable both advanced NTP and advanced Nuclear Electric Propulsion (NEP).

\section{Background}

Development efforts in the United States have demonstrated the viability and performance potential of NTP systems. For example, Project Rover (1955 - 1973) completed 22 high power rocket reactor tests. Peak performances included operating at an average hydrogen exhaust temperature of $2550 \mathrm{~K}$ and a peak fuel power density of $5200 \mathrm{MW} / \mathrm{m}^{3}$ (Pewee test), operating at a thrust of $930 \mathrm{kN}$ (Phoebus-2A test), and operating for an accumulated time of 109 minutes (NF-1 test) [1]. Results from Project Rover indicated that an NTP system with a high thrust-toweight ratio and a specific impulse greater than $900 \mathrm{~s}$ would be feasible. Excellent results have also been obtained by Russia. Ternary carbide fuels developed in Russia may have the potential for providing even higher specific impulses.

Many factors would affect the development of a $21^{\text {st }}$ century nuclear thermal rocket (NTR). Test facilities built in the US during Project Rover are no longer available. However, advances in analytical techniques, the ability to utilize or adapt existing facilities and infrastructure, and the ability to develop a limited number of new test facilities may enable an affordable, viable development, qualification, and acceptance testing strategy for the NCPS. Although fuels developed under Project Rover had good performance, advances in materials and manufacturing techniques may enable even higher performance fuels. Potential examples include cermet fuels and advanced carbide fuels. Precision manufacturing will also enable NTP performance enhancements.

NTP will only be utilized if it is affordable. Testing programs must be optimized to obtain all required data while minimizing cost through a combination of non-nuclear and nuclear testing. Strategies must be developed for affordably completing required nuclear testing. A schematic of an NCPS engine is shown in Figure 1.

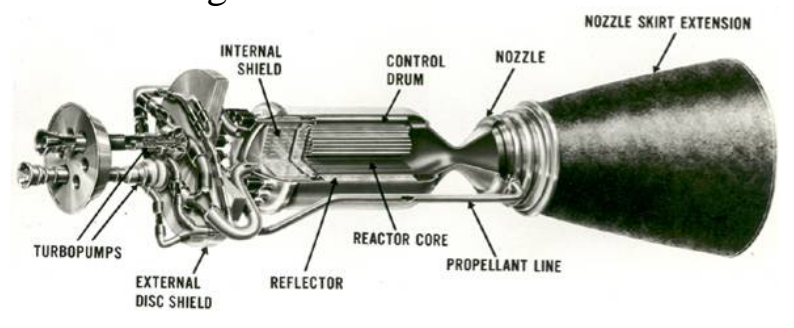

Figure 1. Schematic of an NCPS engine. 
The Nuclear Cryogenic Propulsion Stage Project

NASA's Nuclear Cryogenic Propulsion Stage (NCPS) project was initiated in October, 2011, with the goal of assessing the affordability and viability of an NCPS. Key elements of the project include 1) Preconceptual design of the NCPS and architecture integration; 2) Development of a High Power ( $\sim 1$ MW input) Nuclear Thermal Rocket Element Environmental Simulator (NTREES); 3) NCPS Fuel Design and Testing; 4) NCPS Fuels Testing in NTREES; 5) Affordable NCPS Development and Qualification Strategy; and 6) Second Generation NCPS Concepts. The NCPS project involves a large ( $\sim 50$ person) NASA/DOE team supplemented with a small amount of procurement funding for hardware and experiments. In addition to evaluating fundamental technologies, the team will be assessing many aspects of the integrated NCPS, and its ability to significantly enhance or enable NASA architectures of interest.

\section{Pre-Conceptual Design of the NCPS and Architecture Integration}

The NCPS is an in-space propulsion system/stage using fission as the energy source to heat propellant (hydrogen) and expand it though a nozzle to create thrust. The increase in engine performance available from even a first generation NCPS would enable more ambitious exploration missions, both robotic and human. It is the intent of the NCPS project to develop a pre-conceptual design of a first generation stage with one or more nuclear thermal rocket(s) capable of interfacing with soon to be available launch vehicles and possible payloads and missions. The design must utilize technologies that are readily available with minimal risk to development. The design must take into account the development viability/feasibility, affordability, and potential reusability. A strategic method of development must be considered; assessing both commonality and scalability for miniaturization or growth. Other strategic considerations are the testing approach (a combination of terrestrial and space testing to validate the engine) and the need for sustained funding.

The NCPS must show relevance to the U.S. space exploration goals and must provide a development path toward a feasible, affordable, and sustainable Nuclear Cryogenic Propulsion Stage. United States' National Space Policy (June 28, 2010, pg. 11) specifies that NASA shall: By 2025, begin crewed missions beyond the Moon, including sending humans to an asteroid. By the mid-2030s, send humans to orbit Mars and return them safely to Earth. The NCPS design will focus on ensuring maximum benefit to human Mars mission, although the NCPS could have numerous other applications as well. Detailed studies are ongoing, building on work performed in previous programs [2].

NCPS mission analysis and definition will stay synchronized with the NASA Human Architecture Team (HAT) for application toward future human missions and the currently developing Space Launch System (SLS).

One potential SLS configuration would help maximize the benefit from the NCPS by balancing mass and volume constraints.

The sensitivity of NCPS performance to specific impulse, engine thrust-to-weight ratio, and other parameters is being assessed as one initial step in stage design. The design of the NCPS will favor proven and tested technologies and the design will also identify critical technologies that will be required for development.

A historical perspective for a common, scalable fuel element will help provide flexibility 
in design. During the Rover program, a common fuel element / tie tube design was developed and used in the $50 \mathrm{klb}_{\mathrm{f}}$ Kiwi-B4E (1964), $75 \mathrm{klb}_{\mathrm{f}}$ Phoebus-1B (1967), $250 \mathrm{klb}_{\mathrm{f}}$ Phoebus-2A (June 1968), and $25 \mathrm{klb}_{\mathrm{f}}$ Pewee engine (Nov-Dec 1968).

To help ensure affordability, the NCPS must take maximum advantage of technologies, components, and subsystems that are developed elsewhere in the architecture, as well as provide input and requirements to those technologies to obtain the capabilities needed for effective integration of the NCPS. The NCPS must also stay coordinated with the SLS and upper Cryogenic Propulsion Stage (CPS) projects to take advantage of common elements and to leverage technologies and configurations to reduce cost.

The NCPS project will also evaluate Bimodal Nuclear Thermal Electric Propulsion (BNTEP). The design of such a system would likely be more complex than the design of either a pure NEP system or a pure NTP system, but there could be potential performance advantages. For applications requiring small amounts of electricity, a simpler system could be used to provide that power, especially for missions that will have limited access to solar energy. Both propulsion-only and "bimodal" (propulsion and power) systems will be assessed under the NCPS Project.

To support the NCPS design effort, available analytical tools will be enhanced and refined. The Department Of Energy (DOE) has developed sophisticated computer modeling tools for nuclear system design. Since the initial fuel elements under consideration are very similar to those previously developed under the Rover/NERVA and other programs, the NCPS will be able to take advantage of these available models. In addition, NASA rocket system simulation tools will be applicable.
The computational modeling tools from DOE and NASA will allow needed trade studies and mission analysis. Initial efforts will focus on benchmarking of the nuclear models with test data and/or between similar models. After confidence in the nuclear models has been established, an iterative design process will begin convergence of NASA and DOE models for best design solutions.

One engine system model under consideration is the closed expander cycle, which derives fluid-pumping power from excess heat generated within the engine and passes the entire propellant flow through the nozzle. The cycle is currently of interest due to its high Isp performance. However, several other candidate cycles have been considered in the past and will be evaluated. Also, hydrogen is the most desirable propellant based on its thermodynamic properties; similarly for high Isp performance. However, hydrogen is also very challenging to store for long duration missions without significant boil-off losses and will require technology refinement. Liquid hydrogen also has a very low density and high volume tanks are advantageous for many missions. Other potential propellants will be evaluated in the engine balance studies, and in-situ propellant usage is also a consideration.

The safety of all rocket engines (including nuclear engines) is paramount. Although a nuclear engine is essentially non-radioactive prior to operation at significant power, the engine must be designed to avoid inadvertent start. This is particularly true for times when individuals could be in close proximity to the reactor, such as launch processing. Safety of the nuclear engine will be ensured via design and by drawing on over seven decades of reactor operating experience.

Crew health and safety may benefit from the use of an NCPS. The NCPS may enable 
shorter mission times (reducing crew exposure to microgravity, cosmic rays, solar flares, and other hazards) or increased payload mass (allowing for increased shielding, supplies, or equipment.

\section{Nuclear Thermal Rocket Element Envi- ronmental Simulator (NTREES):}

A high temperature, high power density fissile fuel form is a key technology for an NCPS. In addition, affordable development and qualification of the fuel form is important to overall NCPS affordability. Fuel life and performance is largely limited by mass loss in a hot gas/cyclic environment. Hence a major milestone of the NCPS project is the completion of the 1-MW Nuclear Thermal Rocket Element Environmental Simulator (NTREES) test chamber. The purpose of the NTREES facility (including an arc heater and a compact hydrogen test chamber) is to perform realistic non-nuclear testing of nuclear thermal rocket (NTR) fuel elements and fuel materials. Although the NTREES facility cannot mimic the neutron and gamma environment of an operating NTR, it can simulate the thermal hydraulic environment within an NTR fuel element to provide critical information on material performance and compatibility.

Initial upgrades to NTREES have been completed. The hydrogen system has been upgraded to enable computer control through the use of pneumatically operated variable position valves (as opposed to manual hydrogen flow control). The upgrade also allows hydrogen flow rate to be increased to 200+ $\mathrm{gm} / \mathrm{sec}$. The operational complexity of NTREES has been reduced by consolidating controls and reworking the purge system so as to permit simplified purging operations.

Prior to initiating the second stage of modifications, NTREES was used to test a "fuel el- ement like" test article. The purpose of the test was to evaluate the behavior of the fuel and to demonstrate the test capabilities of NTREES. The test element consisted of a 12 inch long, 5/8 inch diameter specimen having seven hydrogen flow holes. The materials comprising the test element consisted of pure tungsten with 40 volume \% hafnium nitride particles encased in 0.030 inch niobium can. The total duration of the tests was about 4.5 hours at maximum induction heater power (about $30 \mathrm{~kW}$ ). The tests were performed in flowing hydrogen at a flow rate equivalent to what would be expected in a NERVA type engine operating at full power (about 0.7 $\mathrm{gm} / \mathrm{sec}$ ). Ten power cycles equivalent to about 2.5 Mars missions were performed on the fuel element. Because no suitable insulation was available for the test element so as to prevent high heat losses from radiation and convection processes, the nominal operating temperature of the test element was approximately $1300 \mathrm{~K}$. Nevertheless, in one brief test sequence in which there was no hydrogen flowing, the temperature in the test element approached $2100 \mathrm{~K}$. A picture of the specimen under test is presented in Figure 2.

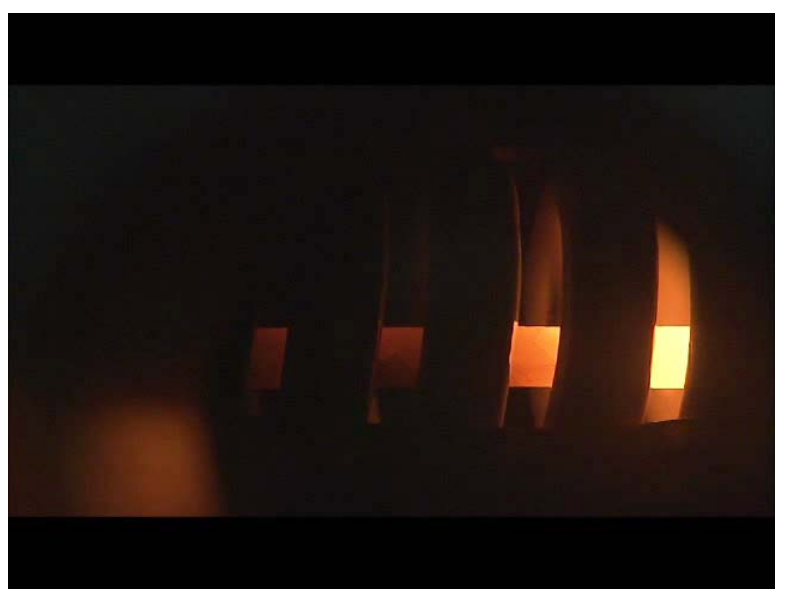

Figure 2. Material Specimen under Test in Flowing Hydrogen in NTREES

In the second stage of modifications to NTREES, the capabilities of the facility will be increased significantly. In particular, the 
current $50 \mathrm{~kW}$ induction power supply will be replaced with a $1.2 \mathrm{MW}$ unit which will allow more prototypical fuel element temperatures to be reached. To support this power upgrade, the water cooling system will also be upgraded to be capable of removing $100 \%$ of the heat generated during testing. Also required will be the upgrade of the nitrogen system and the complete redesign of the hydrogen nitrogen mixer assembly. In particular, the nitrogen system will be upgraded to increase the nitrogen flow rate from its current $1.2 \mathrm{lb} / \mathrm{sec}$ to at least $4.5 \mathrm{lb} / \mathrm{sec}$. The mixer upgrade will incorporate a number of design features which will minimize thermal stresses in the unit and allow for the increased flow rate of nitrogen and water required by the increased operational power level. The new setup will require that the NTREES vessel be raised onto a platform along with most of its associated gas and vent lines. The induction heater and water systems will then be located underneath the platform. The new design will also allow for additional upgrades which could take the power level of NTREES to $5 \mathrm{MW}$. Once fully operational, the 1-MW NTREES test chamber will be capable of testing fuel elements and fuel materials in flowing hydrogen at pressures up to $1000 \mathrm{psi}$, at temperatures up to and beyond $3000 \mathrm{~K}$, and at near-prototypic reactor channel power densities. NTREES will be capable of testing potential fuel elements with a variety of propellants, including hydrogen with additives to inhibit corrosion of certain potential NTR fuel forms; however the focus of FY 2012 activities will be on pure hydrogen propellants.

The NTREES facility is licensed to test fuels containing depleted uranium. It includes a pyrometer suite to measure fuel temperature profiles and a mass spectrometer to help assess fuel performance and evaluate potential material loss from the fuel element during testing. Additional diagnostic upgrades planned for NTREES include the addition of a gamma ray spectrometer located near the vent filter to detect uranium fuel particles exiting the fuel element in the propellant exhaust stream and to provide additional information of any material loss occurring during testing. Using propellant fed from gas storage trailers located external to the facility, NTREES is configured to allow continuous, uninterrupted testing of fuel elements for any desired length of time. A picture of the most recent operational NTREES primary chamber configuration is shown in Figure 3.

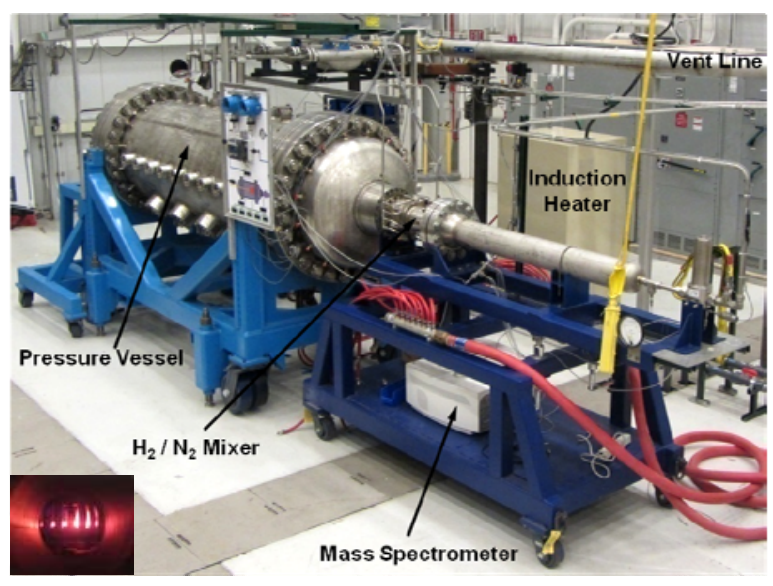

Figure 3. Nuclear Thermal Rocket Element Environmental Simulator

Additional test facilities includes an operational arc heater (Figure 3) that is capable of flowing hot hydrogen over a material or fuel sample at a hydrogen gas temperature of up to $3160 \mathrm{~K}$ for approximately 30 minutes which will be used for the preliminary vetting of material samples.

Also available will be a compact test chamber capable of testing small fuel samples at high temperatures in a hydrogen environment. This small fuel sample test facility is called the Compact Fuel Element Environmental Test facility, or CFEET (Figure 4). 
This project will also develop a detailed understanding of the energy deposition and heat transfer processes in NTREES, along with effects on material mechanics and fluid/material interaction, to better improve future test conditions and obtain as much information as possible to accurately extrapolate non-nuclear test data to real reactor conditions.

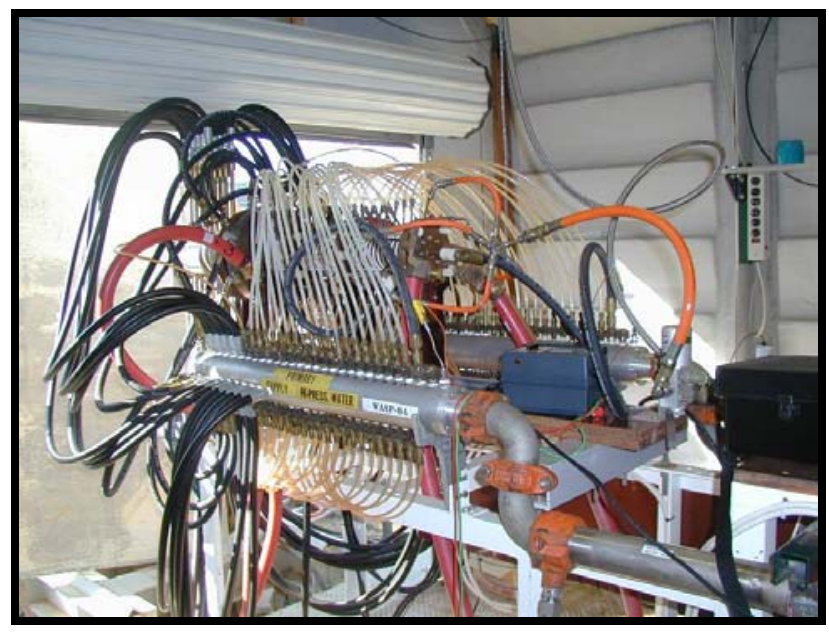

Figure 3. Arc Heater

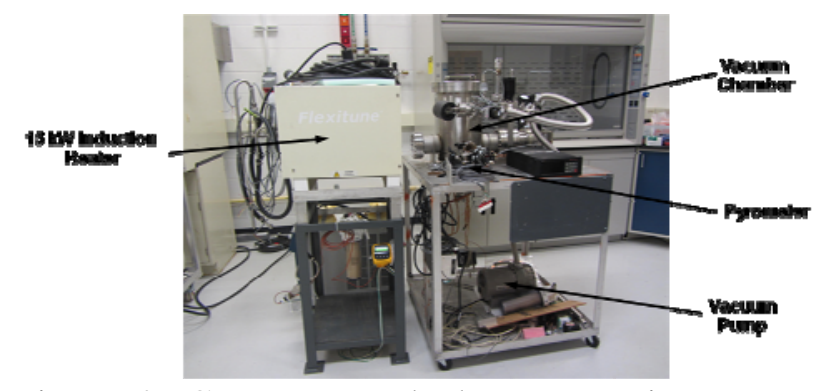

Figure 4. Compact Fuel Element Environmental Test facility (CFEET)

\section{$\underline{\text { NCPS Fuel Design / Fabrication }}$}

Early fuel materials development is necessary to validate requirements and minimize technical, cost, and schedule risks for future exploration programs. The development of a stable fuel material is a critical path, long lead activity that will require a considerable fraction of program resources. The objective of the NCPS Fuel Design and Fabrication task is to demonstrate materials and process technologies for manufacturing robust, fullscale CERMET and graphite fuel elements. The elements will be based on the starting materials, compositions, microstructures, and fuel forms that were demonstrated on previous programs. The development will be a phased approach to recapture key technologies and produce quality fuels. Samples will then be tested in flowing hot hydrogen to understand processing and performance relationships. As part of this demonstration task, a final full scale element test will be performed to validate robust designs. These demonstrations are necessary to enable a future fuel material down select and a potential follow on non-nuclear ground test project. A major focus of the NCPS project is the use of a highly integrated NASA/DOE fuels development team. The goal is to enhance and utilize existing infrastructure and capabilities to minimize cost.

Current research at MSFC and INL is focused on developing fabrication processes for prototypical W/UO2 CERMET fuel elements.

CERMETS are typically formed by densification of powders using Powder Metallurgy (PM) processes. Tungsten based CERMETS with surrogate ceramic particles have been fabricated to near theoretical density using Hot Isostatic Press (HIP) and Pulsed Electric Current (PEC) techniques. During HIP, the CERMET powders are consolidated in sacrificial containers at $2000^{\circ} \mathrm{C}$ and pressures up to $30 \mathrm{ksi}$. The PEC process consists of high speed consolidation of powders using DC current and graphite dies. For both HIP and PEC processing, the powder size and shape, powder loading, and processing parameters significantly affect the quality and repeatability of the final part. Figure 5 shows a typical microstructure and image of a net shape consolidated CERMET part. The part is a 19 hole configuration that had uniform shrinkage dur- 
ing consolidation and good tolerance on the flow channel geometry.
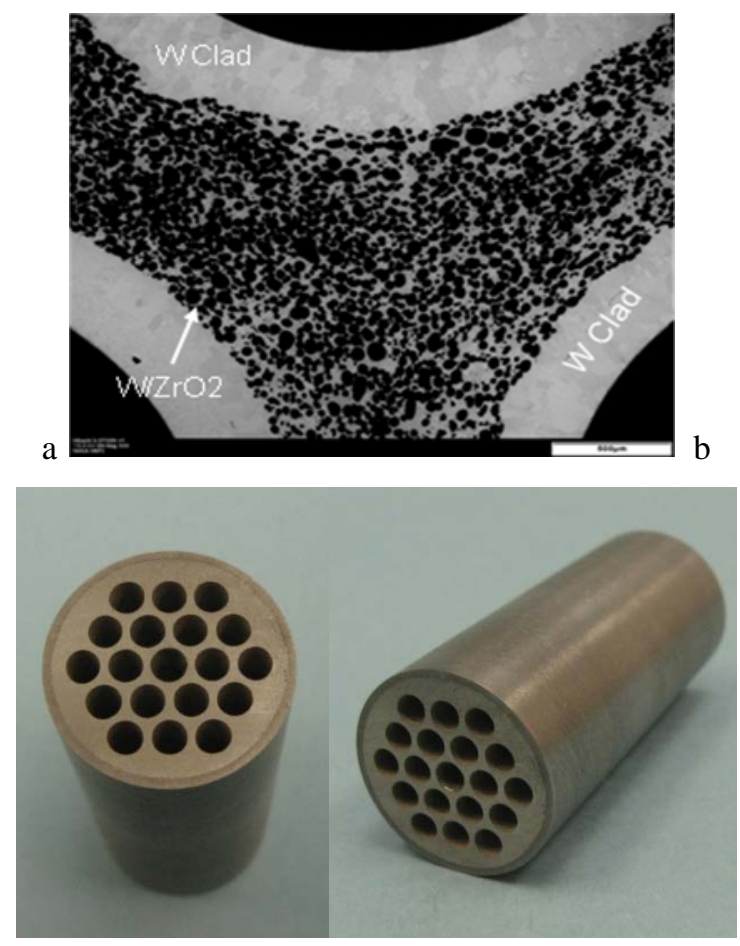

Figure 6. a) Micrograph of a W/60 vol\% $\mathrm{ZrO}_{2}$ CERMET with integral $\mathrm{W}$ claddings

b) Consolidated W/40 vol\% HfN CERMET sample.

The nature of this initial task is rapid materials and process screening as a precursor to the detailed development that will be required to fully optimize and qualify a CERMET fuel. CERMET materials and processes were demonstrated at subscale level on previous efforts, but there are significant technical and programmatic challenges for key technologies. Some of the materials and process approaches being developed to maximize performance are the size of the fuel particles and resultant shape in the consolidated part, CVD tungsten coating of spherical $\mathrm{UO}_{2}$ particles prior to consolidation, complete surface cladding of the elements with tungsten, and additions of small amounts of fuel particle and matrix stabilization materials such as $\mathrm{Gd}_{2} \mathrm{O}_{3}$.

Significant work is also being done at ORNL to recapture Rover/NERVA graphite compo- site fuel materials. Various graphite based fuels consisting of $\mathrm{UO}_{2}, \mathrm{UC}_{2}$, or $(\mathrm{U}, \mathrm{Zr}) \mathrm{C}$ particles in a graphite matrix were tested in the Rover/NERVA program. The materials were successfully demonstrated in full scale nuclear test engines. However, the fuel materials and fabrication technologies are not currently available. The NCPS task is focused on developing the graphite composite extrusion and $\mathrm{ZrC}$ coating capabilities. The composite fuel matrix is a carbide-based ceramic fuel composition consisting of uranium carbide, zirconium carbide and graphite materials. Subscale matrix samples are being fabricated and tested to demonstrate microstructure and properties. In parallel, coating trials are being performed on short elements for hot hydrogen testing at MSFC. The goal is to validate recapture of the graphite composite fuel materials using full scale testing of a Rover/NERVA fuel element. Figure 7 shows images of Phoebus reactor fuels from the 1960s.
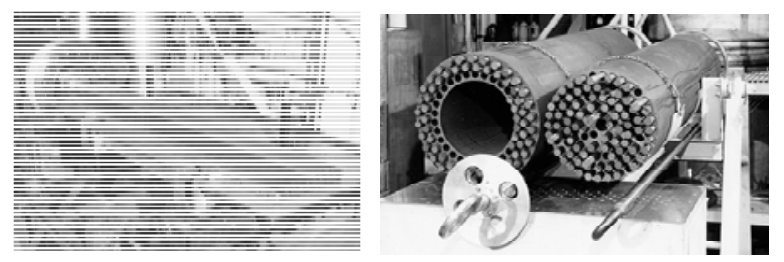

Figure 7: Images of the Rover/NERVA Phoebus Reactor fuels.

\section{NCPS Fuels Testing in NTREES}

Testing in NTREES will range from fuel sample testing using the CFEET to the testing of near-prototypic fuel elements. A primary goal of the testing is to demonstrate adequate fuel performance and to increase confidence in fuel system designs (e.g. materials, coatings, geometries) prior to potential nuclear testing. CERMET and graphite composite samples will be thermal cycle tested in a static and flowing environment. Several iterations of testing will be performed to evaluate fuel mass loss impacts from density, microstructure, fuel particle size and shape, chem- 
istry, claddings, particle coatings, and stabilizers. Initial subscale testing will be performed in the CFEET system. The CFEET test samples will be approximately 0.5 ” diameter $x$ 3" length for solid slug and prototypic 7-hole channel configurations. Testing of solid slugs will be performed to baseline performance prior to introducing geometric variables.

The 7-hole channel configuration was chosen for CFEET screening to rapidly evaluate thermal cyclic affects on prototypic geometries from surface vaporization, diffusion/migration, and cracking. Testing has shown that fuel mass loss is significantly impacted by thermal cycling and geometry. The prototypical geometry will be much more susceptible to cracking induced migration and volatilization of the exposed fuel particles. The fuel materials and forms such as coated particles, claddings, and stabilizers being evaluated on this effort have all been demonstrated to control fuel migration and loss. The initial screening is not to determine or characterize specific modes of fuel loss or mechanisms. The intent is to verify performance improvements of the materials and processes prior to expensive full scale fabrication and testing. Post test analysis will include weight percent fuel loss, microscopy (SEM, EBSD, and EDS), and dimensional tolerance and cracking.

Subsequent testing of full scale fuel elements will be performed in NTREES. The test samples will be based on the Rover/NERVA and ANL 200MW designs. The goal is to benchmark performance in NTREES for comparison to future materials and process improvements, alternate fabrication processes, and other fuel materials of interest. The iterative materials and process development, CFEET screening, and NTREES testing will continue through FY12-14 NCPS effort with numerous subscale and full scale element testing milestones.

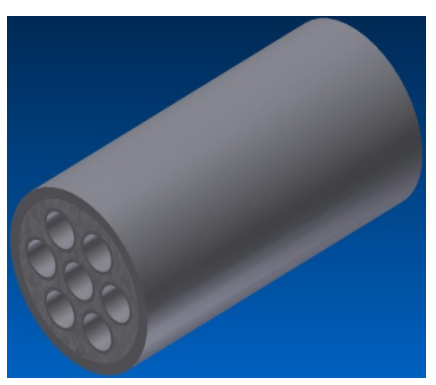

Figure 8: CFEET system and sample configuration

\section{Affordable NCPS Development and Quali- fication Strategy}

This element will focus on ensuring the overall affordability of the NCPS by accounting for all programmatic and engineering considerations, including environmental and security.

The current strategy is to start with a small NTP engine, then increase size, safety factors and redundancy for use with human missions. Focus on non-nuclear testing in the beginning. Utilized as many engine components, subsystems, and test facilities currently funded by other projects or is heritage. Utilize lessons learned from other recent NASA flight development programs. Figure 9 shows the overall strategy.

Lessons learned have been acquired from the $\mathrm{J}-2 \mathrm{X}$ rocket engine program, ARES 1-X Test Flight Program, and X-43A Flight Demo Program. The major factors from the lessons learned include the following: follow NASA standards unless deviation has concurrence from the chief engineer and safety officer, start with low safety factors and evolve, upfront involvement from Safety Mission Assurance (including Risk Management) and Systems Engineering Integration, test development engines to the extremes and test two certification engines for flight with double the 
burn duration and double the number of startups.

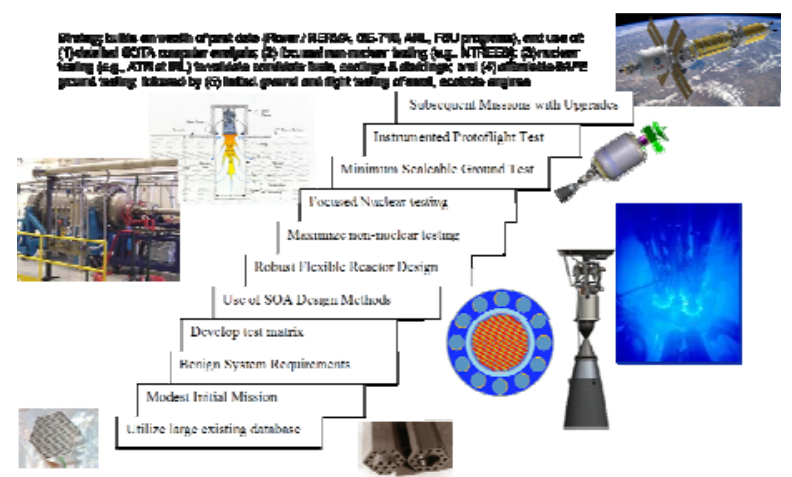

Figure 9. NTP Development Strategy²

The NTP test topology is shown in Figure 10. Past NTP development programs had indepth testing planned involving a ground test complex with a special reactor to test fuel elements, a nuclear furnace for material characterization and critical assemblies to test reactor physics. To save time and money, the current plans are to avoid having a nuclear furnace and fuel element reactor. Focus on nonnuclear testing of the fuel elements, followed by irradiation specimen testing using existing facilities, and use an existing reactor for subelement testing. Final fuel element testing will take place at the full scale ground test facility.

Past NTP ground test facilities for Rover/NERVA are currently not useable. A concept being investigated involves using bore holes at the Nevada Test Site (or a different appropriate site) to filter the engine exhaust. The bore holes are about 1200 feet deep and 8 feet diameter. The soil is made of alluvium. Current soil analysis indicates permeability will allow the hydrogen exhaust gas to rise up through the soil while trapping any radioactive particulates that could potentially be released underground. Back pressures in the bore hole up to 35 psi could take place with a full scale NTP engine and affect the coupling of the engine to the bore hole. More investi- gations are underway. The Subsurface Active Filtering of Exhaust (SAFE) concept is shown in figure 11.

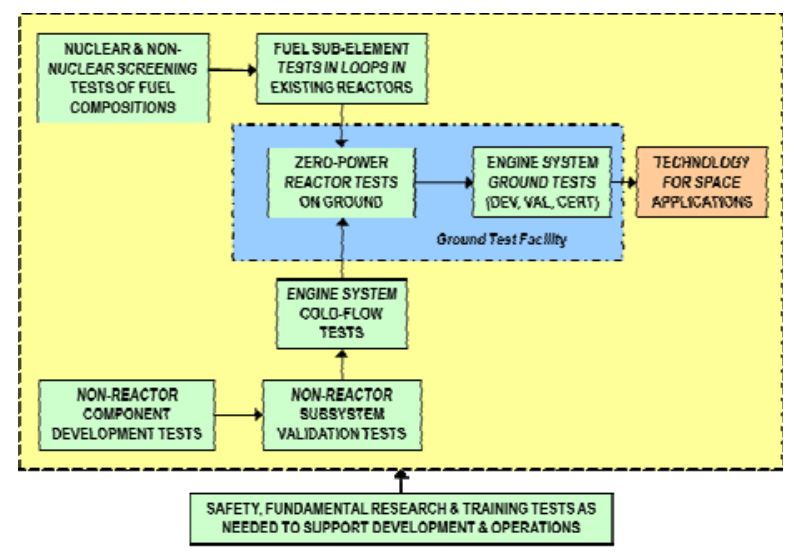

Figure 10. NTP Test Topology

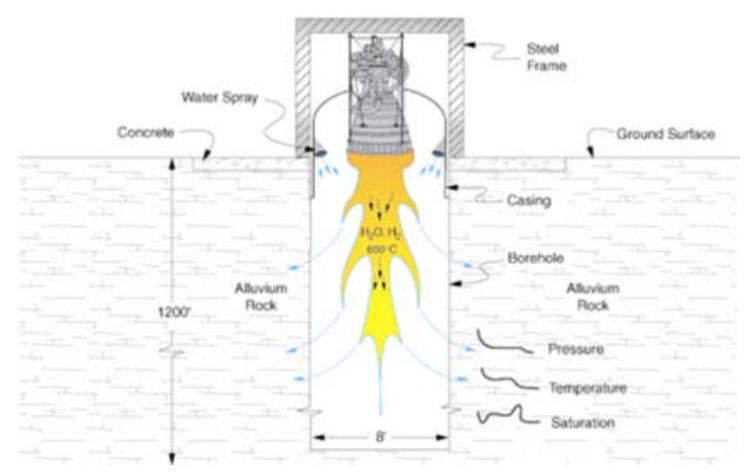

Figure 11. SAFE bore hole concept for full scale NTP testing ${ }^{3}$

In addition to ground testing a full scale NTP engine, a flight demonstration is being investigated to help qualify the engine system and possibly used by a potential customer for a science mission. A very low thrust( $\sim 8 \mathrm{klbf}$ ) engine is being considered to allow for longer burn times and restarts given volume limitations of the payload shroud. Another flight demonstration option could be to use a fullsize ( $25 \mathrm{klbf}$ ) engine operating at either rated or slightly de-rated conditions to gain experience with the actual engine system that could potentially be used to support human Mars 
missions. A flight demo would also allow operation of a high area ratio nozzle, which is truncated for ground testing. Advanced instrumentation and robotics is being investigated to use on the NTP flight demo for inspection of the major engine components. Figure 12 shows similar instrumentation already used on the space shuttle.

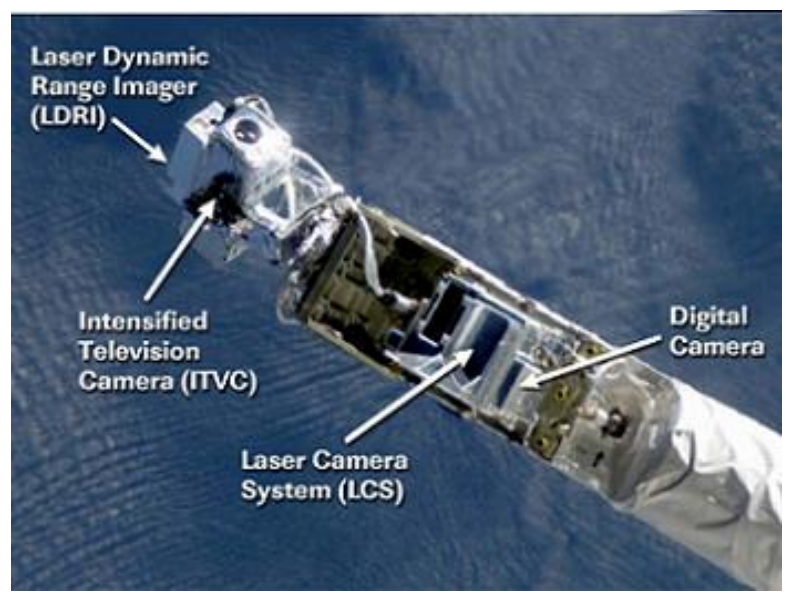

Figure 12. JSC Robotic Instrumentation

A flight demonstration would also demonstrate the capability of the launch facilities to launch fission systems. Although the US has had tremendous success in launching nuclear systems, launch processing for fission systems may be different than launch processing for radioisotope systems. A nuclear safety review and launch approval process is required and shown in Figure 13. The launch approval process could take up to 5 years to complete and needs to be accounted for in the overall development plan.

Both strategies for ground testing and flight demonstration appear to show promise.

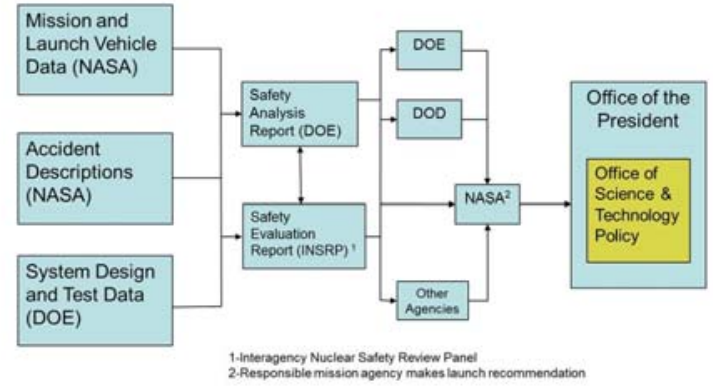

Figure 13. Nuclear Safety Review and Launch approval Process

\section{Second Generation NCPS Concepts}

The "Affordibility" of the NCPS is also indirectly related to the ultimate performance potential of space fission propulsion systems. The future potential for extremely high performance space fission propulsions systems further increases the benefit from NCPS development.

To help assess the eventual performance potential of space fission propulsion systems, a small fraction of the NCPS project is dedicated to second generation systems. In the relatively near term, modern materials and fabrication techniques may enable an NCPS capable of providing an Isp in excess of $1000 \mathrm{~s}$ with a high thrust-to-weight ratio. Radically different design approaches could yield even higher performance. The work being performed under this task will devise new concepts and re-evaluate existing concepts taking into account recent advancement in materials and technologies. Concepts with high performance potential and moderate technology risk (such as ternary carbide encapsulated $\mathrm{UC}_{2}$ ) will receive particular attention. Novel approaches for capitalizing on the unique attributes of fission systems will also be investigated. Such approaches include the direct use of volatiles available in space for NTP 
propellant. This task will also include system concepts for very high performance BNTEP.

Numerous concepts extend the capability of the baseline NTP. These concepts extend the NERVA/Rover design using new fuels and fuel compositions, geometries that promise to increase propellant core temperature efficiency and reduce mass, or involve a completely different method for reaching criticality, such as liquid and gas core systems. These concepts should be investigated for their potential to increase performance.

The vast number of potential concepts means that only a few can be investigated with the resources available on the NCPS project. A three step process is envisioned to select which concepts will receive further attention. First a catalog of existing concepts will be created. This catalog will be in Wiki format so that all team members of the NCPS can contribute. The wiki articles will discuss the fundamental physics of each NTP concept, as well as, their current TRL's, expected performance and development needs.

Second a trajectory parametric will be developed. This parametric will quantify achievable payload ratios for a given specific power and specific impulse. These parametrics will be limited to positive payload ratios and the specific power and impulse combinations that are achievable by nuclear thermal and electric propulsion systems. These parametric curves will be specific to a given mission. Thus one set of payload fraction contours would be developed for a 2-yr round trip mission to Mars, and another for a mission to a particular NEO. Several of these contours will be developed for each mission considered to be of high interest to NASA.

Finally a selection process will identify the best candidate technologies and missions that are achievable with advanced nuclear propulsion. Trajectory parametrics and technology capabilities will be superimposed on one another. Such a combined graph will clearly show which propulsion technologies are suit- ed with which missions. By then factoring in which missions are of highest interest with the research on development difficulty for various propulsion concepts a small set of cases can be selected. These cases will then be investigated further, with detailed modeling of the mission and the propulsion technology. The strength of this process is that if NASA's mission interests change then this data can be used to find more suitable technology candidates.

\section{Conclusion}

The potential capability of NTP is game changing for space exploration. A first generation NCPS based on NTP could provide high thrust at a specific impulse above $900 \mathrm{~s}$, roughly double that of state of the art chemical engines. Near-term NCPS systems would provide a foundation for the development of significantly more advanced, higher performance systems.

\section{$\underline{\text { References }}$}

[1] Koenig D. R. (1986) Experience Gained from the Space Nuclear Rocket Program (Rover), LA-10062-H, Los Alamos National Laboratory, Los Alamos, NM

[2] Borowski S. K., D. R. McCurdy and T. W. Packard (2012) "Nuclear Thermal Propulsion (NTP): A Proven Growth Technology for Human NEO / Mars Exploration Missions,” 2012 IEEE Aerospace Conference, Big Sky, MT, March 3-10, 2012

[3] Bhattacharyya S., "A Rationale Strategy for NTR Development”, AIAA-2011-5945, 47th JPC, San Diego, CA 

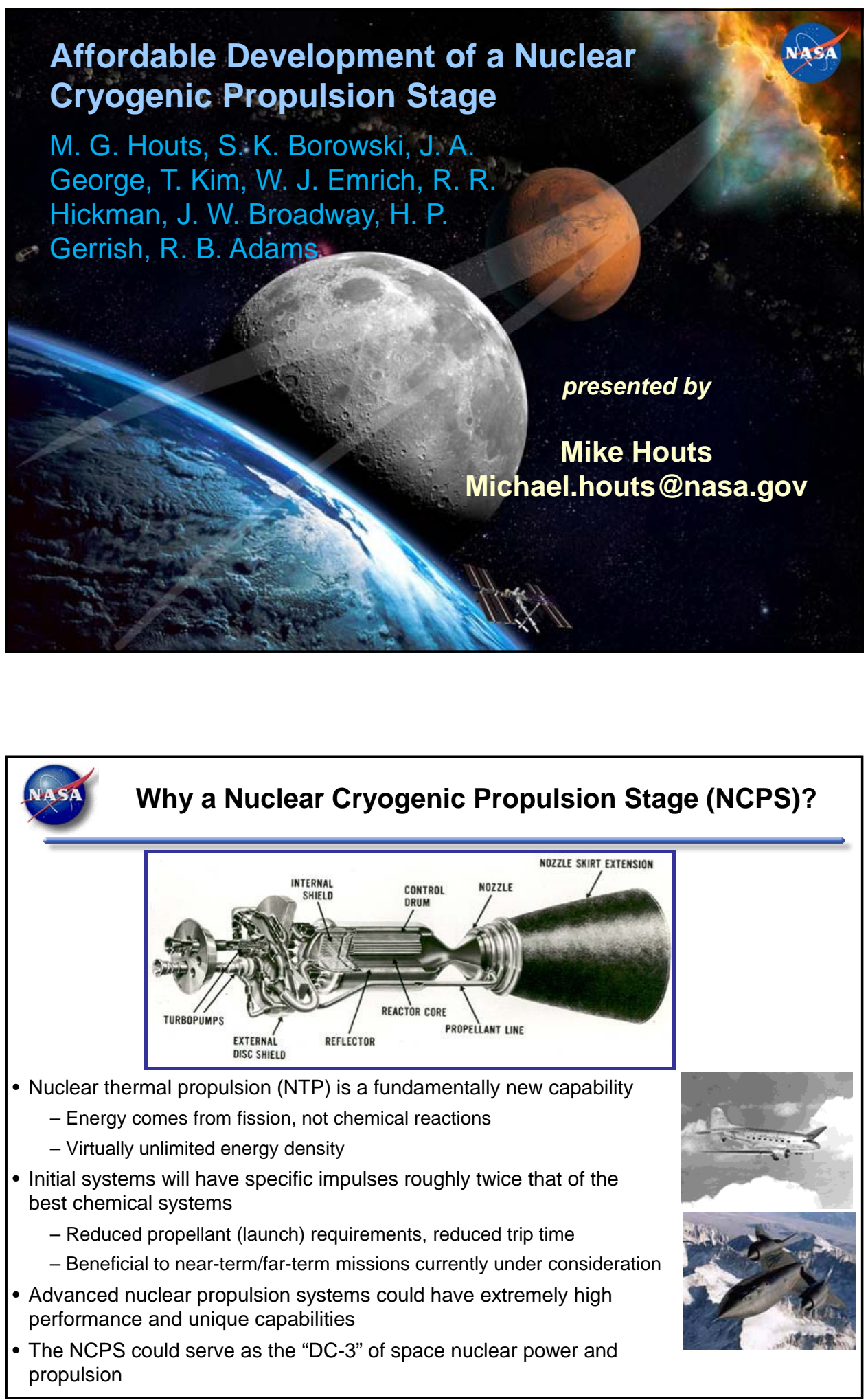


\section{NASA Why a Nuclear Cryogenic Propulsion Stage (NCPS)?}

- NCPS builds on highly successful Rover/NERVA program (1955-1973) and more recent programs.
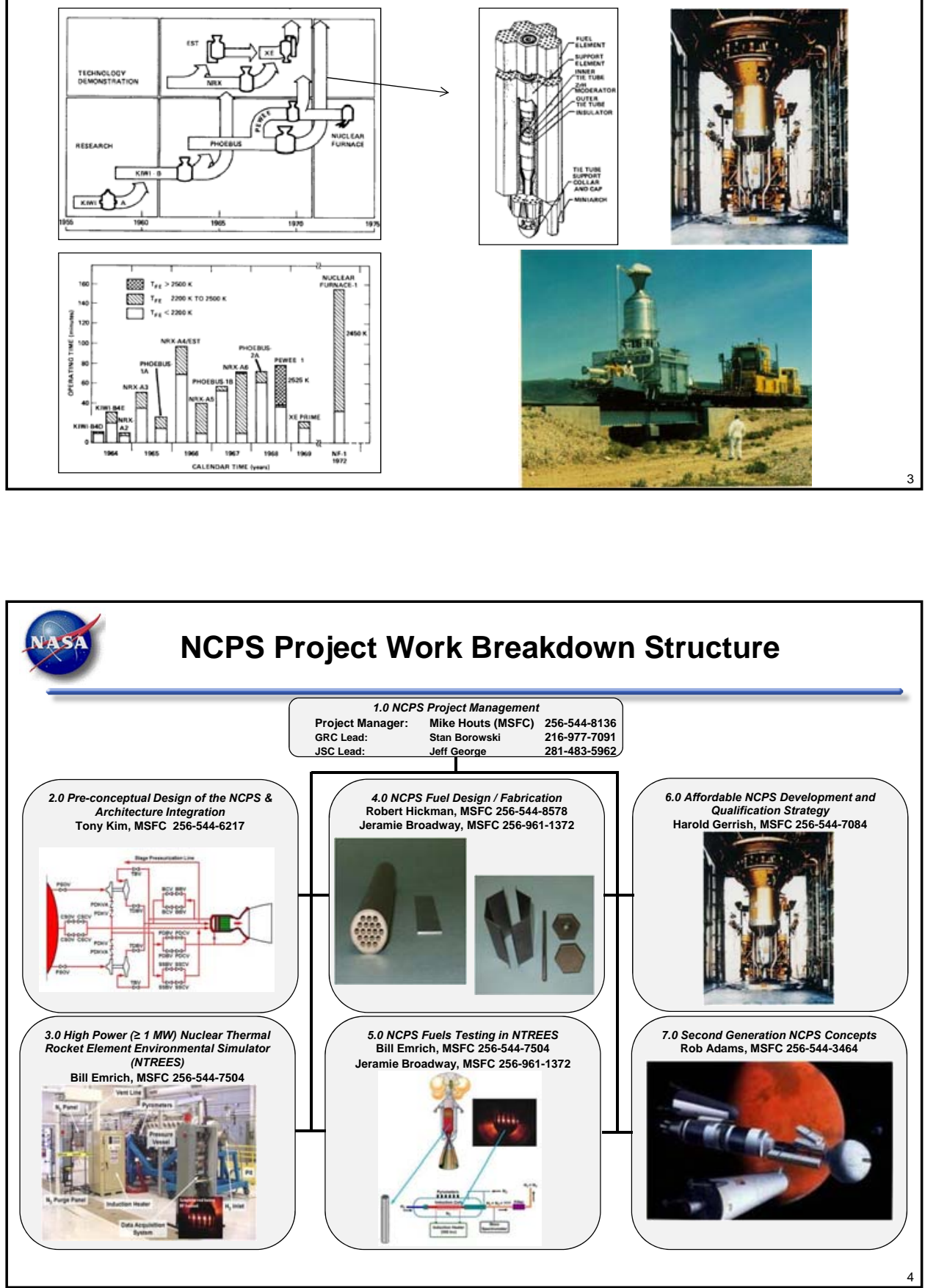

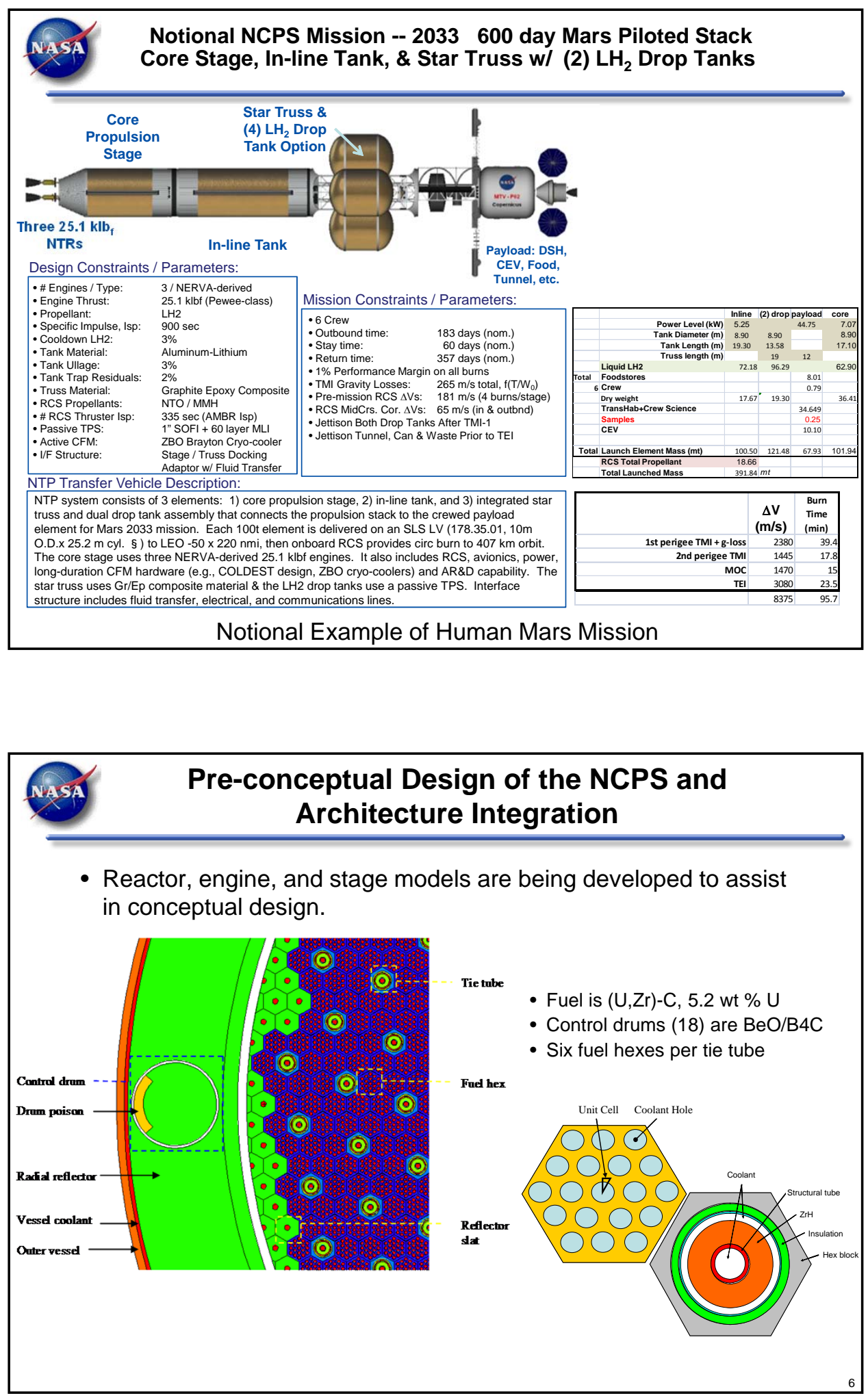

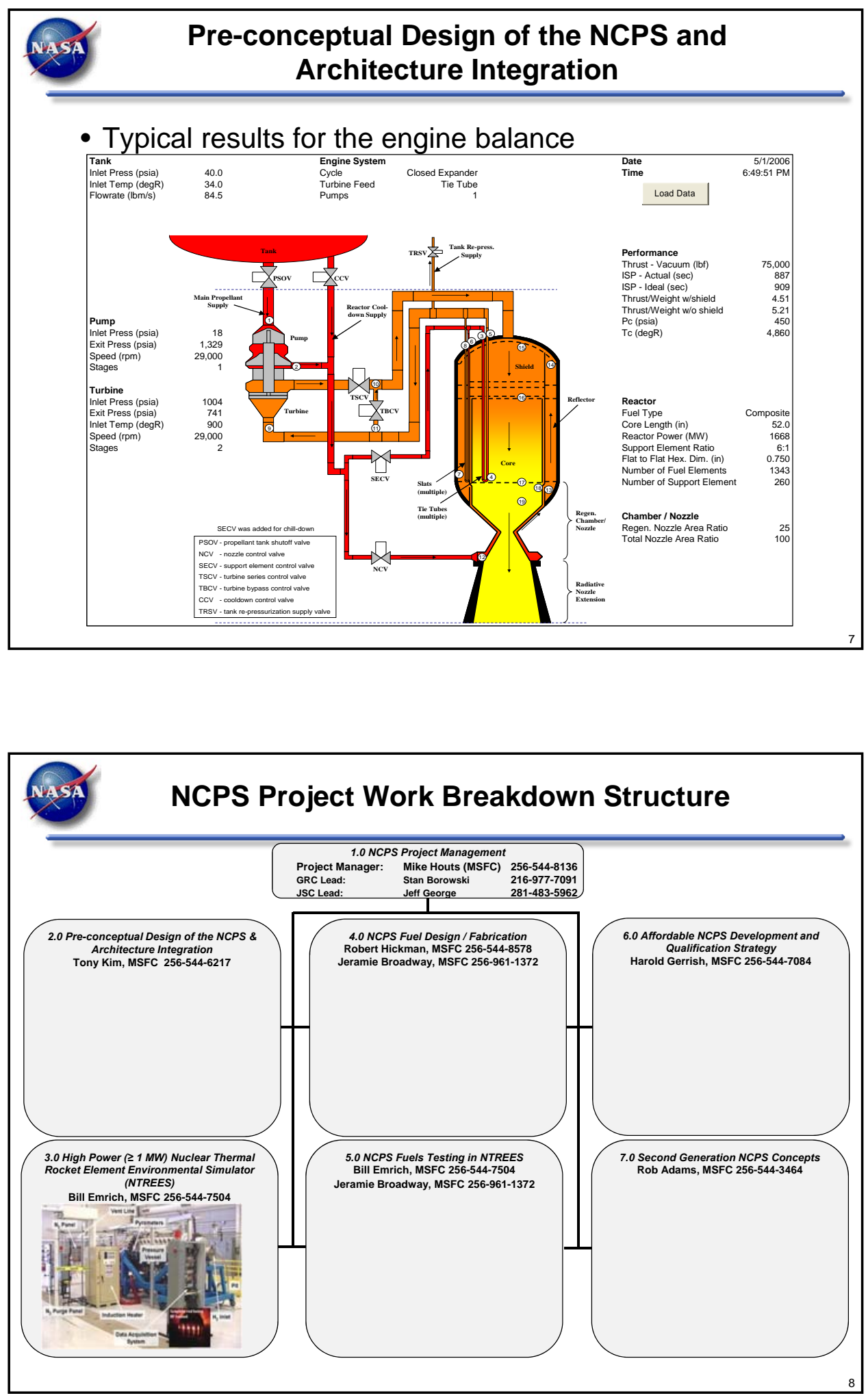


\section{Nuclear Thermal Rocket Element Environmental Simulator (NTREES)}

A key technology element in Nuclear Thermal Propulsion is the development of fuel materials and components which can withstand extremely high temperatures while being exposed to flowing hydrogen. NTREES provides a cost effective method for rapidly screening of candidate fuel components with regard to their viability for use in NTR systems

- The NTREES is designed to mimic the conditions (minus the radiation) to which nuclear rocket fuel elements and other components would be subjected to during reactor operation.

- The NTREES consists of a water cooled ASME code stamped pressure vessel and its associated control hardware and instrumentation coupled with inductive heaters to simulate the heat provided by the fission process.

- The NTREES has been designed to safely allow hydrogen gas to be injected into internal flow passages of an inductively heated test article mounted in the chamber.

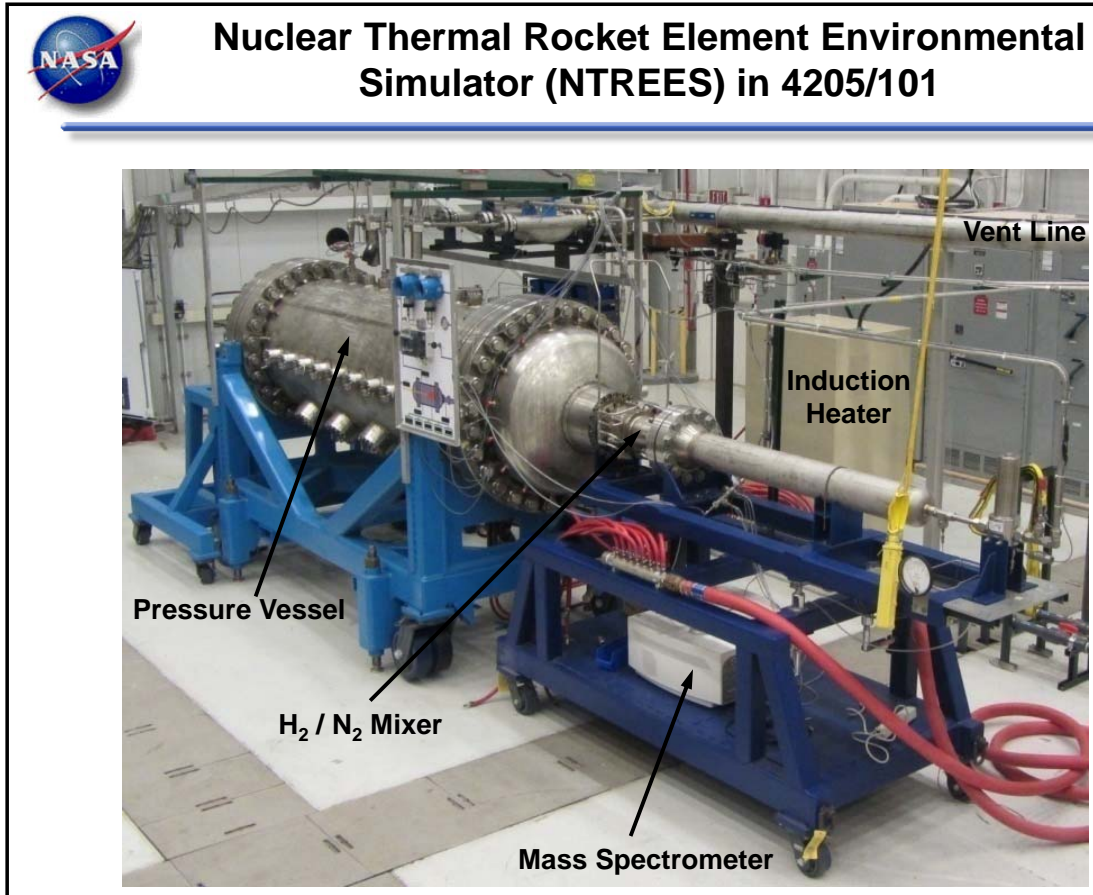




\section{NTREES Undergoing Power Upgrade}

- NTREES induction power supply is being upgraded to $1.2 \mathrm{MW}$

- Water cooling system is being upgraded to remove $100 \%$ of the heat generated during testing

- Nitrogen system is being upgraded to increase the nitrogen flow rate to at least $4.5 \mathrm{lb} / \mathrm{sec}$

- New piping is being installed to handle the increased flow rates

- The $\mathrm{H}_{2} / \mathrm{N}_{2}$ mixer is being upgraded to handle the increased heat loads

- Platform is under construction to allow the new induction heater to be located underneath the NTREES pressure vessel
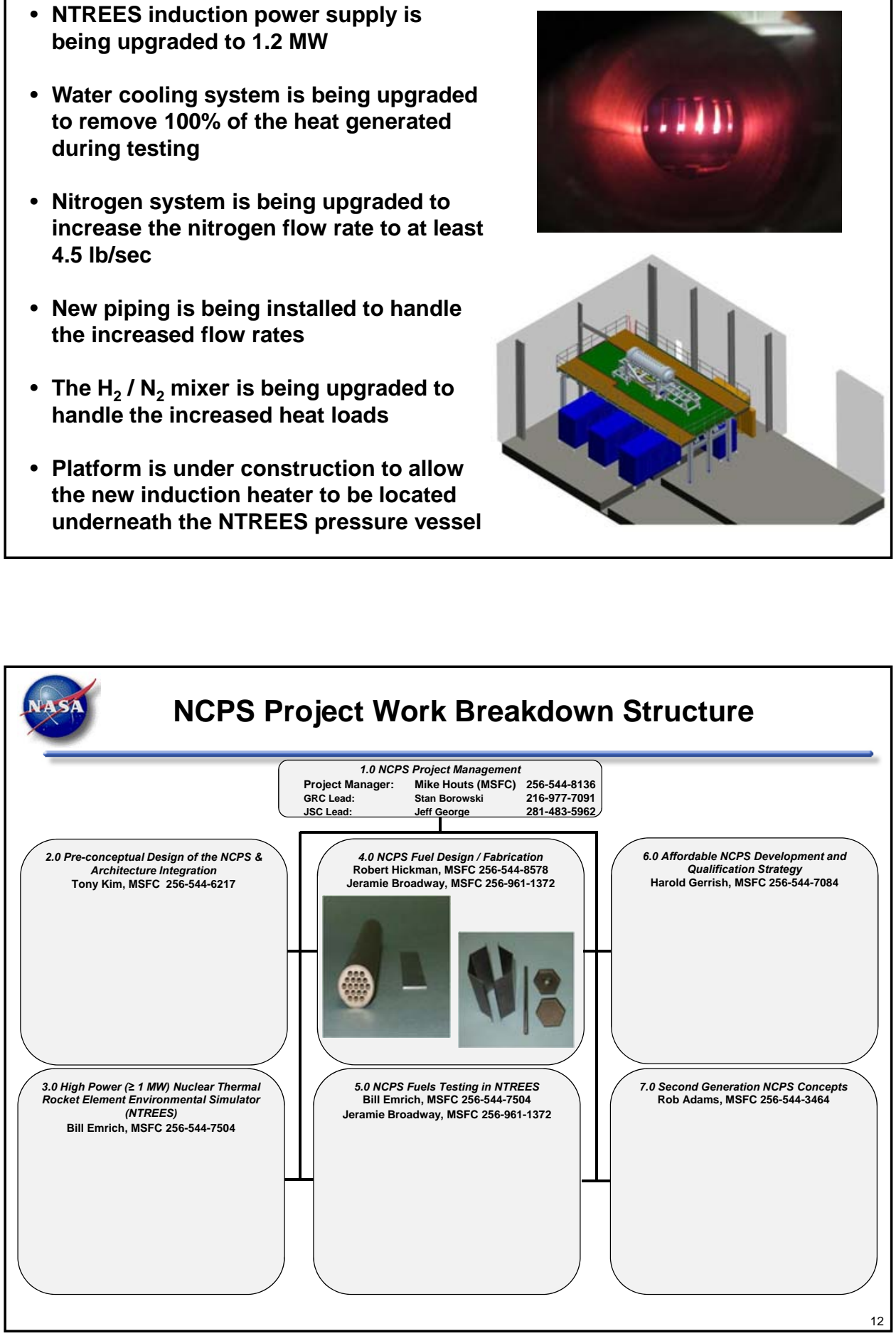


\section{- Objective}

- Optimize advanced manufacturing processes to develop an NTP fuel material

- NASA MSFC and GRC

- Idaho National Laboratory (INL)

- Oak Ridge National Laboratory (ORNL)

- Fabricate CERMET, graphite composite and advanced carbide fuel element samples with depleted uranium fuel particles

- Complete mechanical and thermal property testing to develop an understanding of the process/property/structure relationship

- Characterize samples to determine baseline material properties and evaluate fuel mass loss, matrix cracking, and other thermochemical corrosion processes

- Develop a clear understanding of the fundamental materials impacts on fuel performance

- Key Deliverables

- Design/Fabrication of nuclear thermal rocket fuel element segments for testing in NTREES

- Final Report: NCPS Fuel Element Material Options
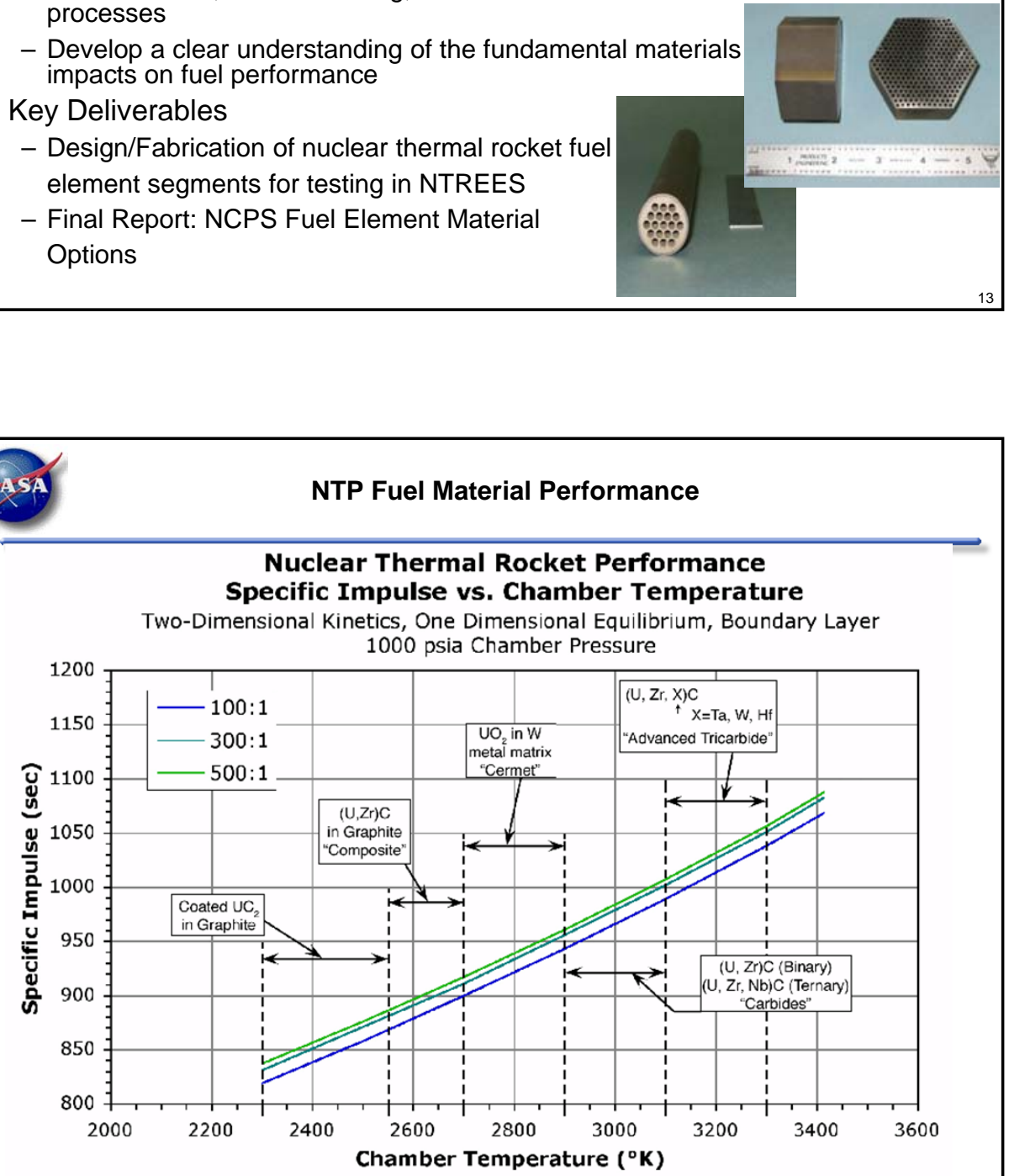


Fuel Material Development
- Develop/evaluate multiple fuel forms and processes in order to
baseline a fuel form for NTP
- CERMET: Hot Isostatic Pressing (HIP), Pulsed Electric Current Sintering (PECS)
- Graphite composites
- Advanced Carbides
Materials and process characterization
- Develop and characterize starting materials
- W coated fuel particles are required for CERMETS
- Particle size, shape, chemistry, microstructure
- Develop and characterize consolidated samples
- Microstructure, density, chemistry, phases
- Optimize material/process/property relationships
- Fuel particle size/shape vs. properties
- Cladding composition and thickness
Hot hydrogen testing
- Early development to validate test approach
- Screen materials and processes (cyclic fuel mass loss)
- Particle size, chemistry, microstructure, and design features (claddings)

Uranium Dioxide (UO2) Particle Development
- UO2 Particle Procurement
- Procured 2kg of dUO 2
- Particle size ranges:
- <100um
- 100um - 150um
- Plasma
- System design complete and currently
being assembled
Operational checkout and spheroidization trials
complete




\section{NASA}

\section{Chemical Vapor Deposition (CVD) Coated Particle Development}

-MSFC Tungsten Hexachloride $\left(\mathrm{WCl}_{6}\right)$ Process Development

- Redesigned and upgraded CVD system complete

- Demonstrated $\mathrm{W}$ coating on $\mathrm{Al}_{2} \mathrm{O}_{3}$ substrate

- Ongoing fluidization trails

- Reactor design optimization for fluidization

-Tungsten Hexafluoride (WF6) Process Development

- Process being developed by Ultramet

- Currently coating $\mathrm{ZrO}_{2}$ particles

- Have demonstrated 20 vol\% W coating

- 40 vol\% W coated spherical particles required for HIP and PECS consolidation process development
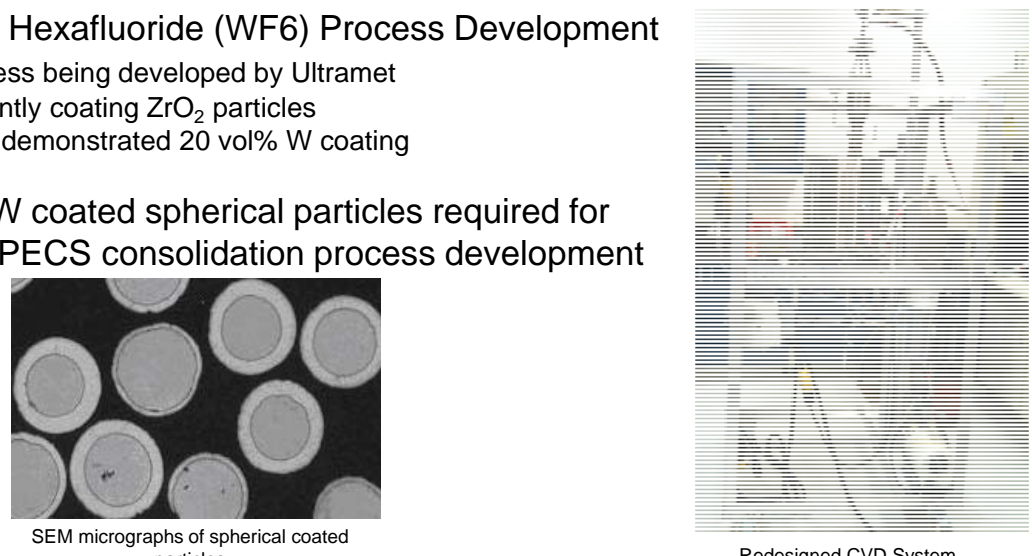

- ANL 200MW element chosen for NCPS reference design

- Hot Isostatic Pressing (HIP) process development

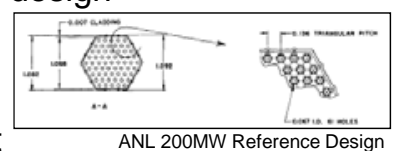

- Completed HIP can designs for sample geometries being considered

- Procured $\mathrm{CeO}_{2}$ surrogate powders currently being spheroidized

- Pulsed Electric Current Sintering (PECS) Development

- Completed pure W microstructural morphology study

- Fabricated 7 specimens of $\mathrm{W}-40 \mathrm{vol} \% \mathrm{CeO}_{2}$ with varying ratios of particle sizes, $\mathrm{W}$ vs. $\mathrm{CeO}_{2}$ (uncoated)

- $\mathrm{CeO}_{2}$ encapsulated $\mathrm{W}$ particles when $\mathrm{W}>\mathrm{CeO}_{2}$ (microstructure image shown)

- Studies ongoing for $\mathrm{CeO}_{2}>\mathrm{W}$ particle size

- EDM machining investigated as a method to drill coolant channels into $\mathrm{W}-\mathrm{CeO}_{2}$ specimens

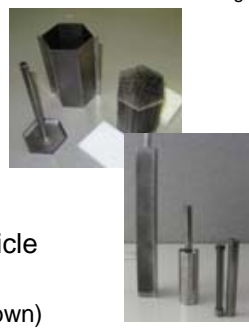




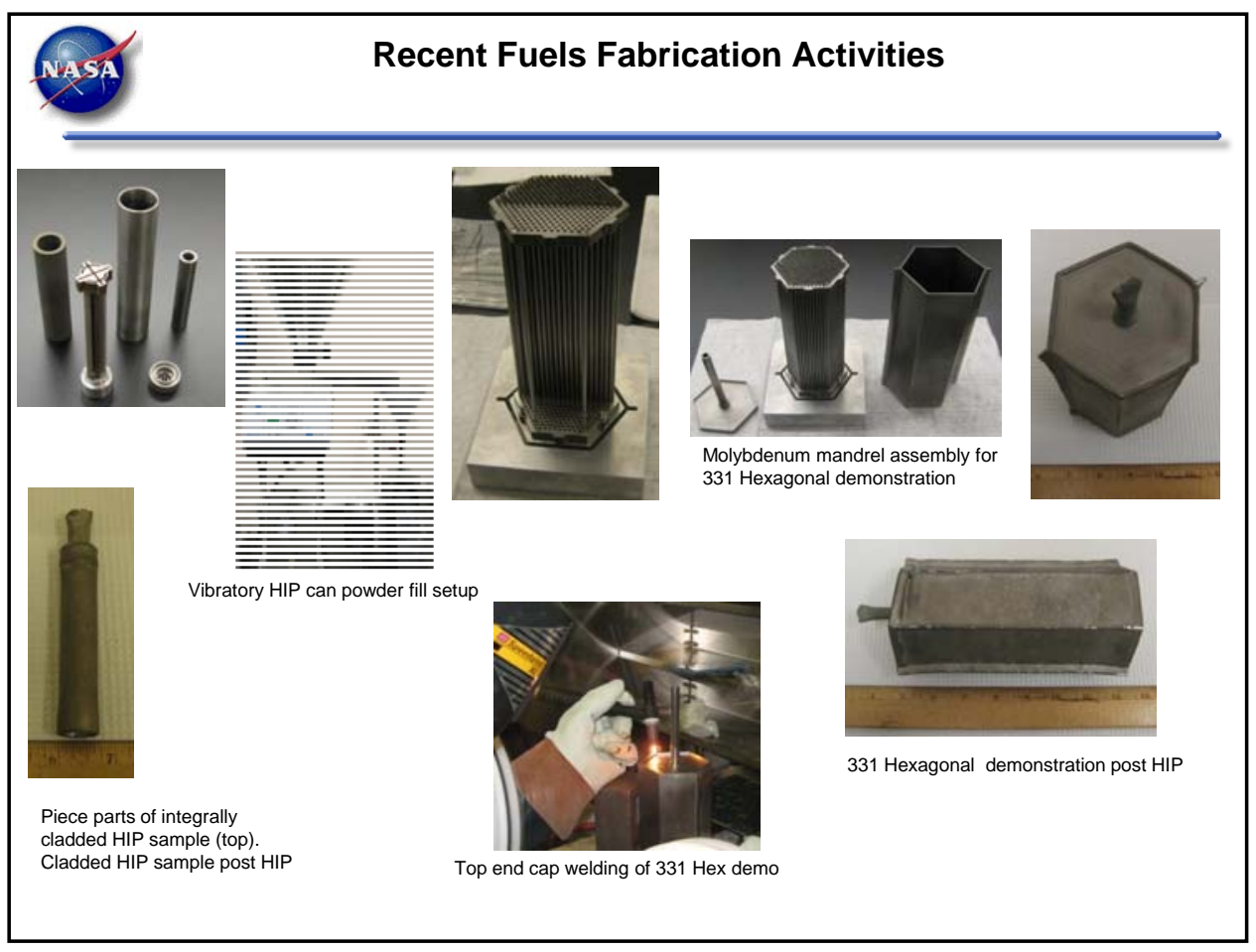

Advanced Carbide Fuel Development
- Advanced Carbides: Ceramic fuel elements fabricated from uranium
carbide $(\mathrm{UC})$ and 1 or more refractory metal carbides (e.g.
$\left.\left(\mathrm{U}_{0.1}, \mathrm{Zr} \mathrm{r}_{0.58}, \mathrm{Nb}_{0.32}\right) \mathrm{C}_{0.95}\right)$
- Development Plan
- Literature search regarding materials \& past efforts
- Preliminary fabrication trials planned for 2012
to assess processing \& performance
- Present focus on refractory transition metals
(groups IVB - VIB, periods 4 - 6 of periodic table)
Parameters under consideration:
- Crystallographic phase relationships
- Melting point/ vaporization rate
- Diffusion characteristics
- Thermal conductivity
- Cost/availability
- Thermal expansion
- Hydrogen compatibility/reactivity
- Neutron absorption cross-section
- Thermal shock characteristics
- Potential fabrication methods
- Ceramic reaction-sintered coatings (CRSC)
- Assist in assessment of potential
- advanced carbide compositions
- Assist in graphite composite fuel element coatings



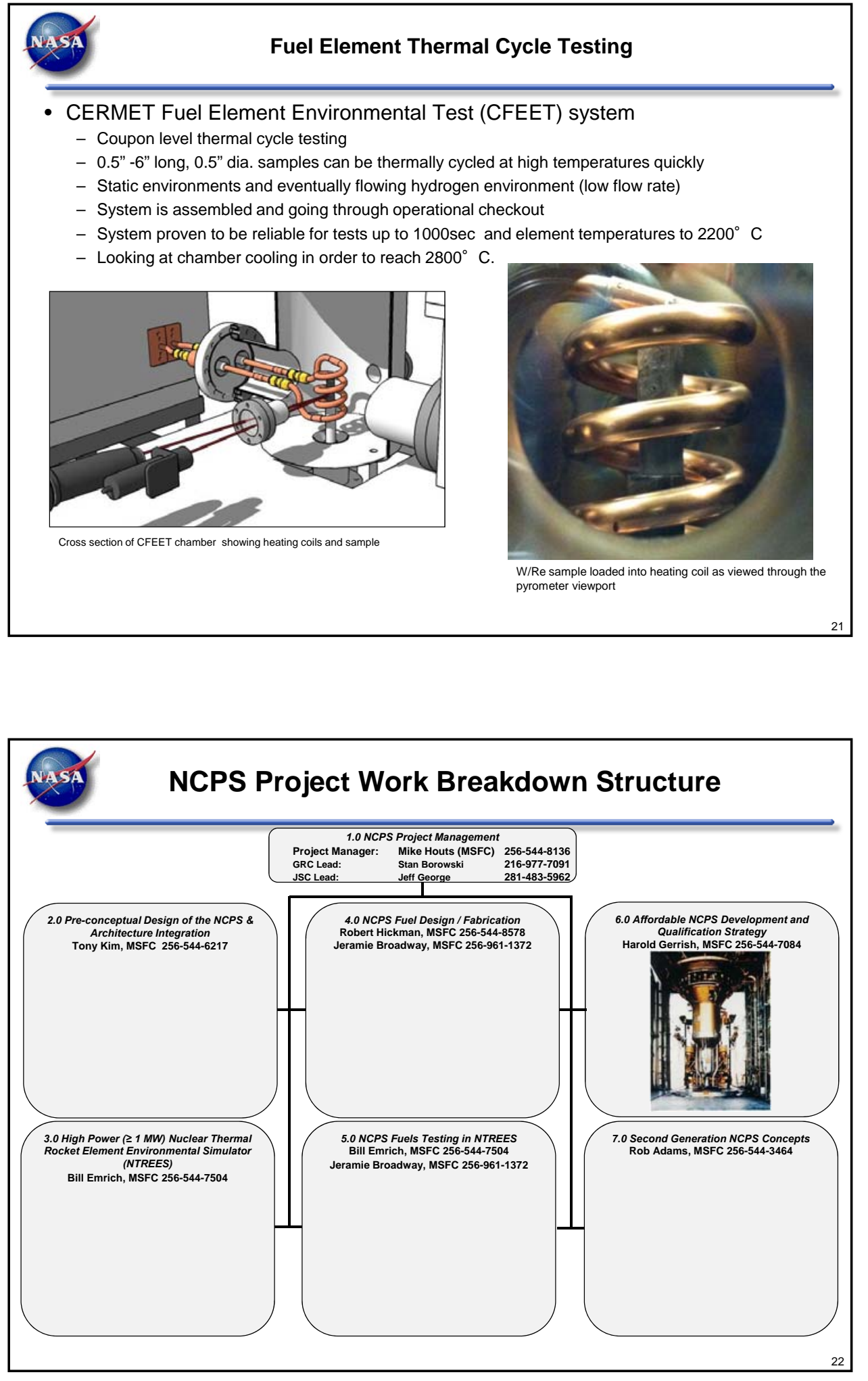

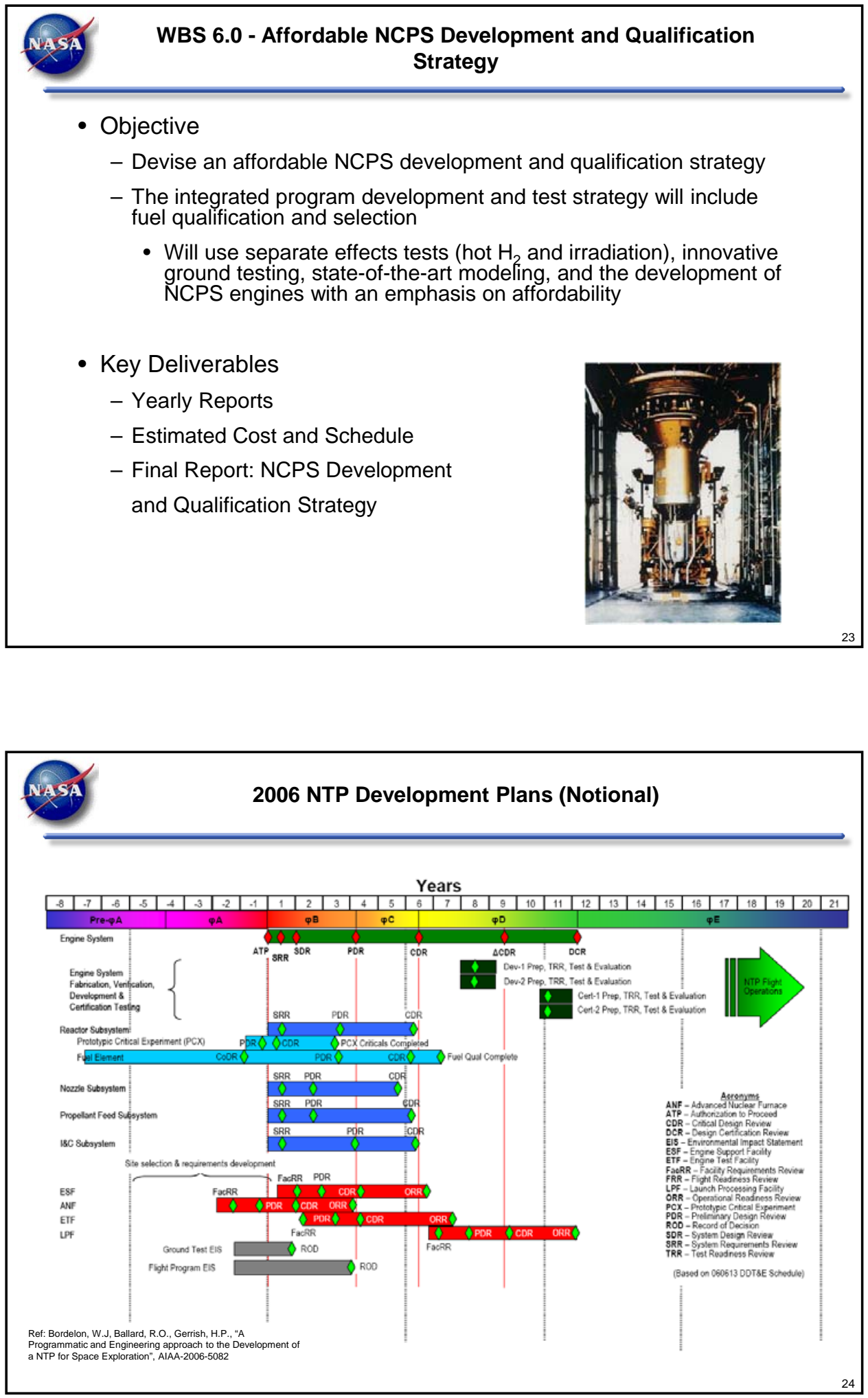

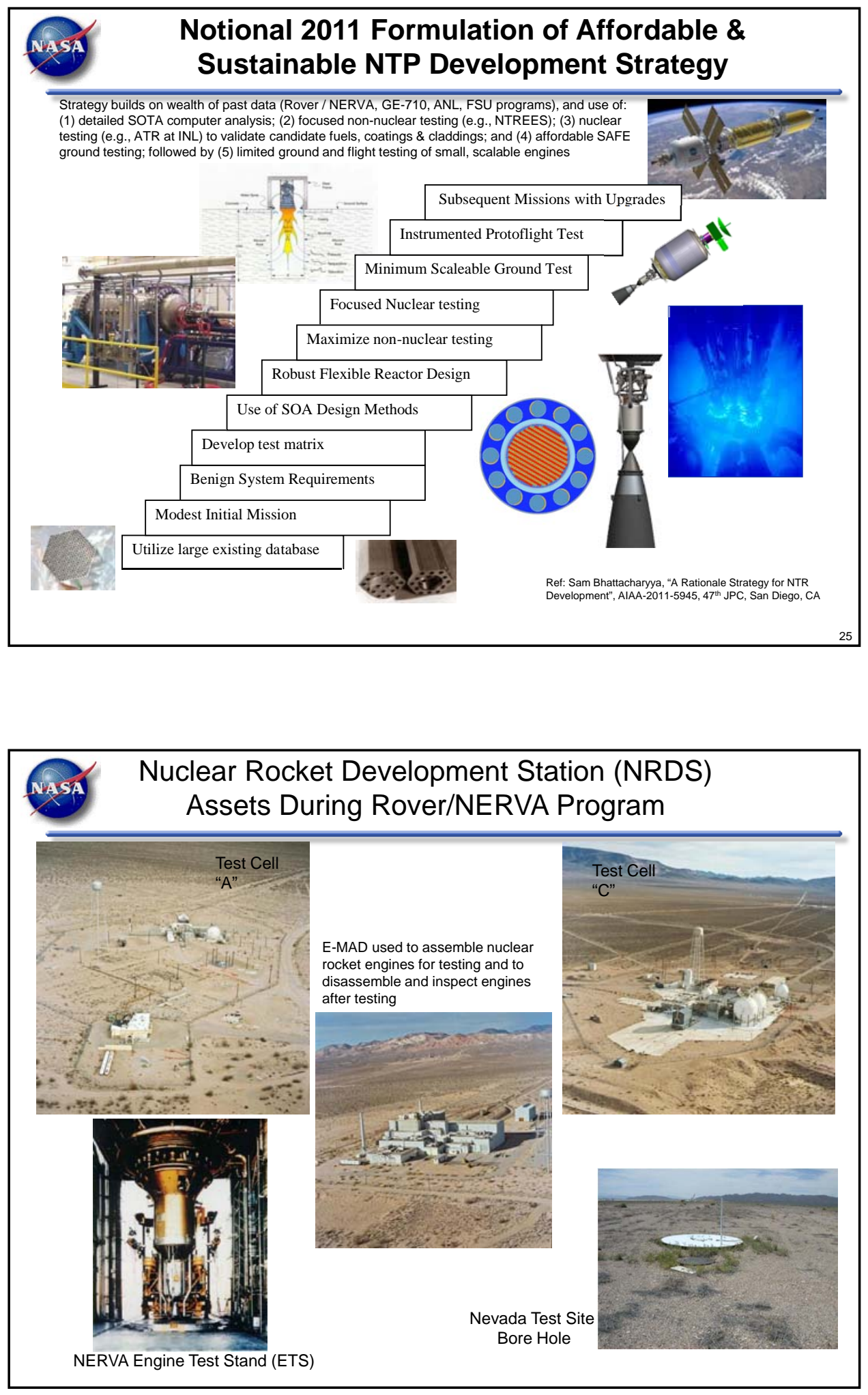

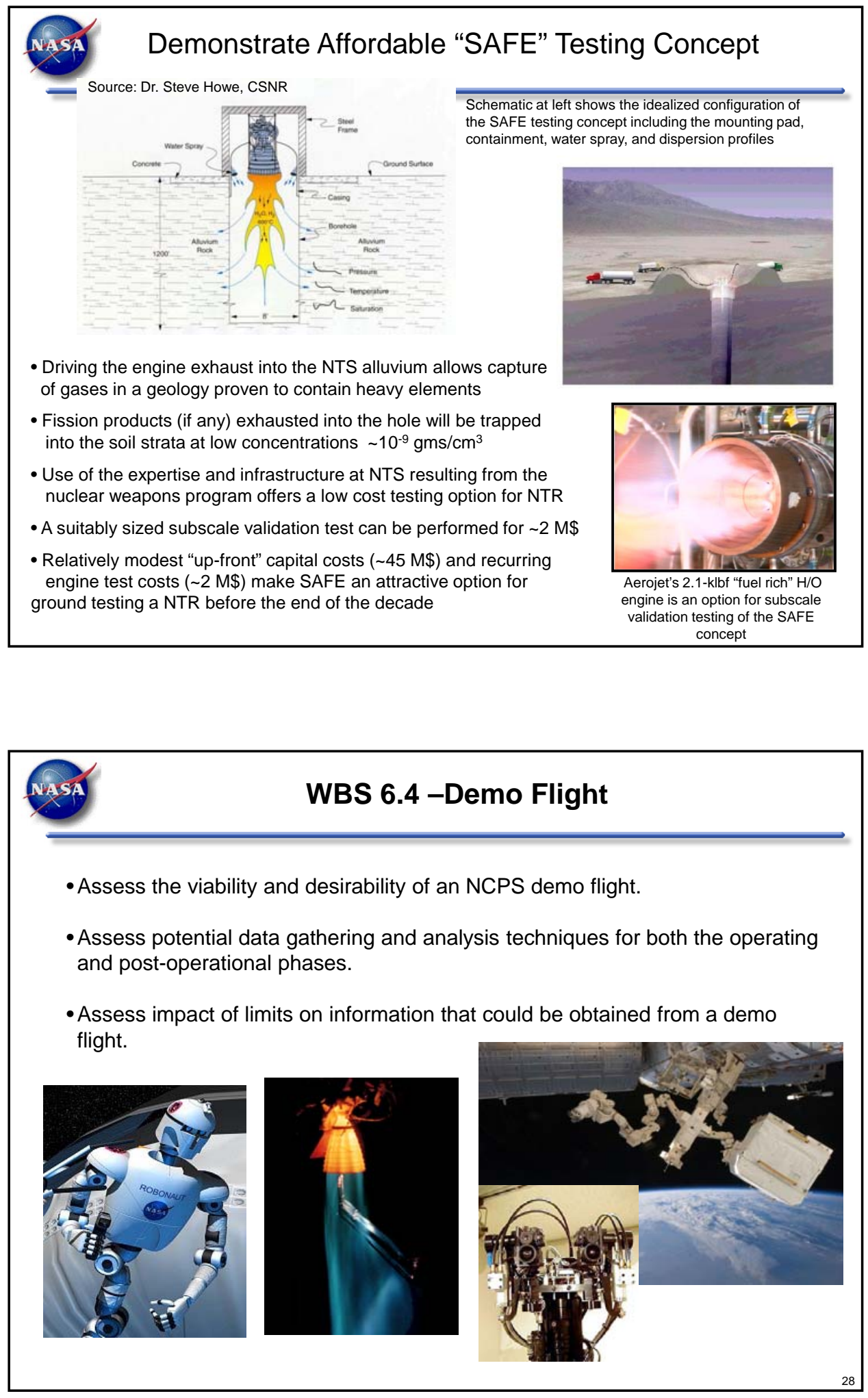


\section{Accomplishments:}

- Coordinated with the SLS program the draft capabilities of each SLS block (I, IA, II). The data will be used to determine how each block can be used for a nuclear cryogenic upperstage or a Mars transfer vehicle.

- Participated in SLS trade to determine the best SLS fairing length and shape. The larger the diameter and longer the length, the better for NTP.

Next:

- Stage sizing and performance trades (done under task\#2)

- Collect cost and schedule from other upperstages

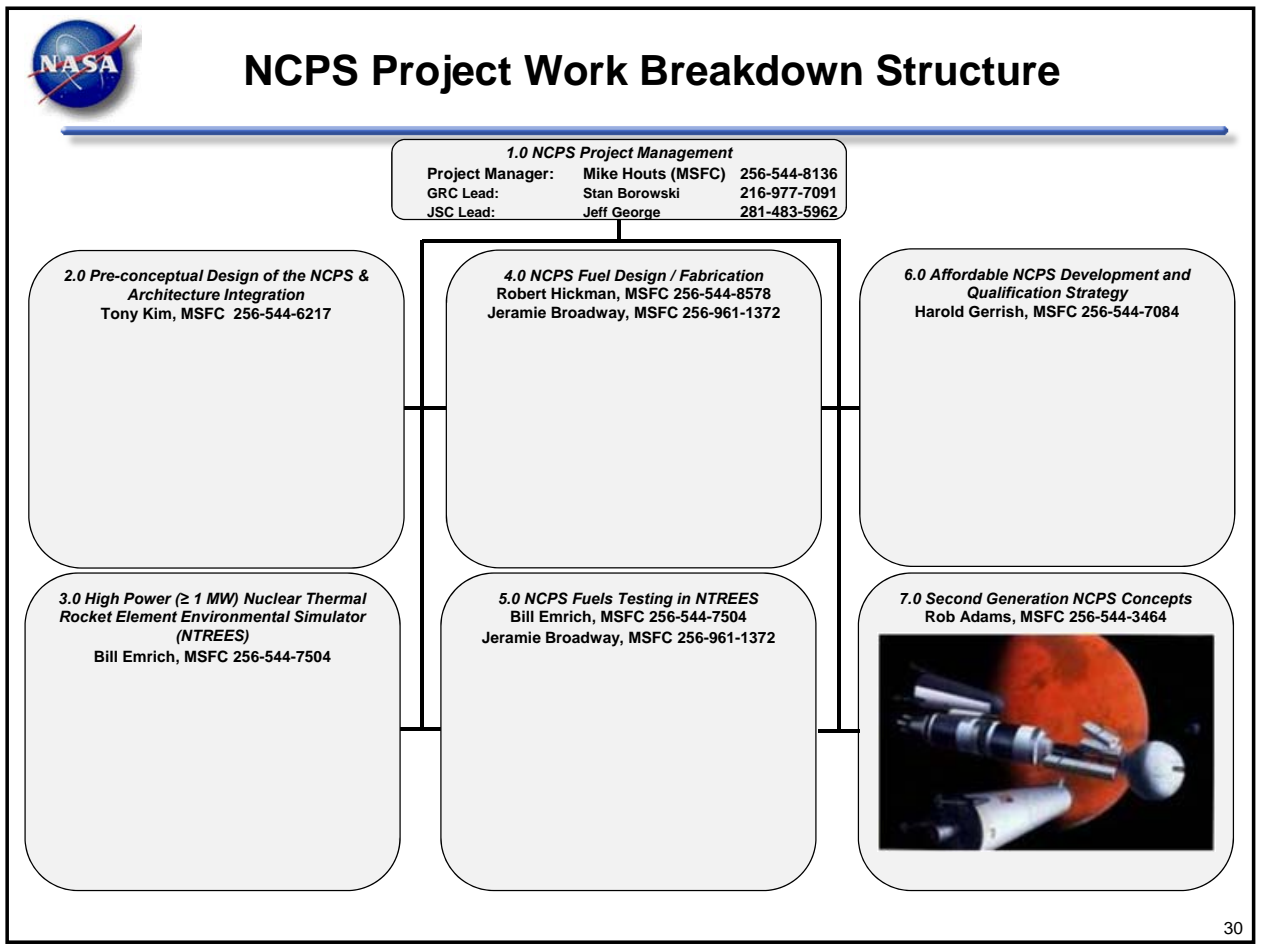




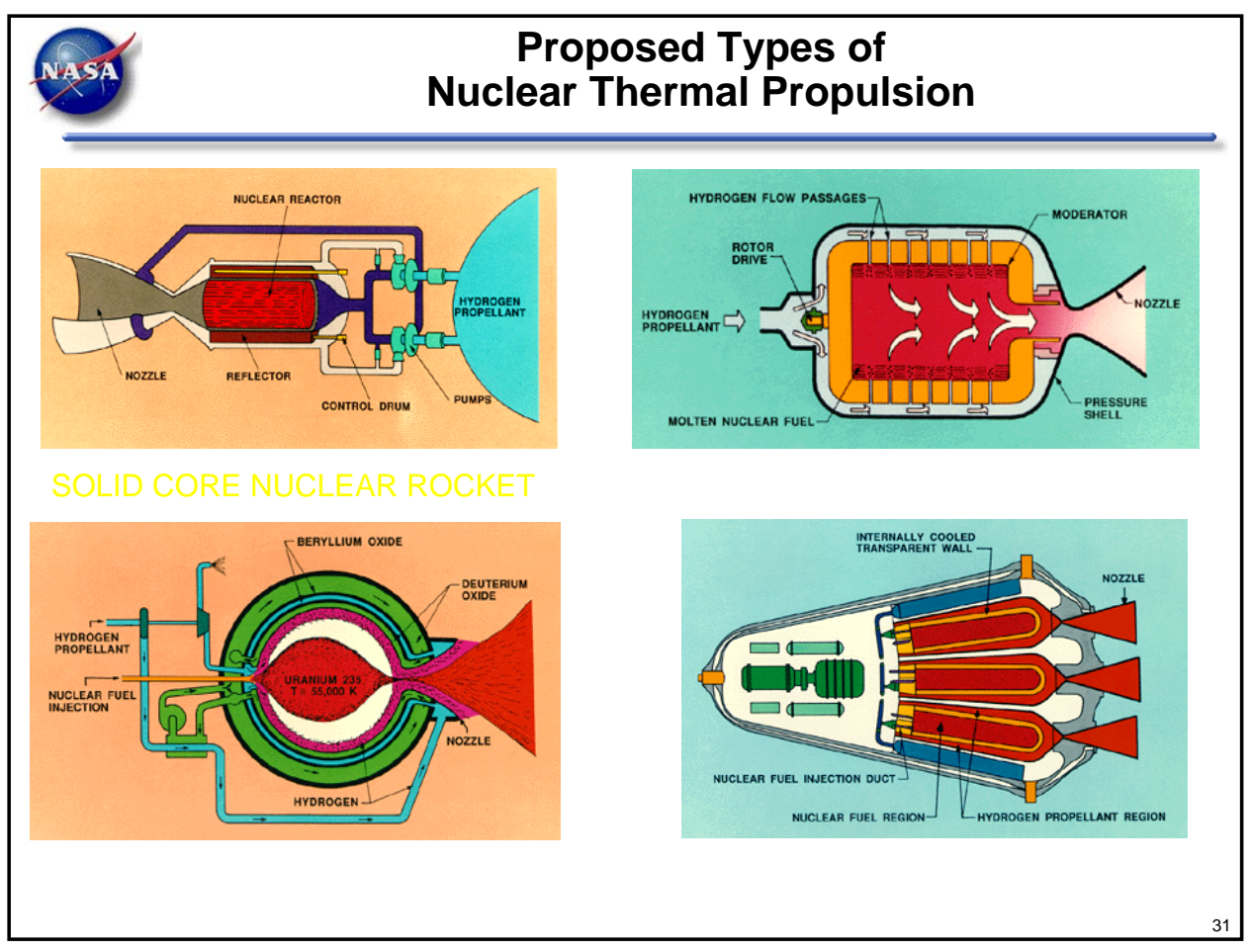

\section{NASA}

\section{Future Plans / Path Forward}

- Space nuclear power and propulsion are game changing technologies for space exploration.

- The NASA NCPS project has 1 to 3 years to demonstrate the viability and affordability of a Nuclear Cryogenic Propulsion Stage.

- Participation is encouraged. Please feel free to contact the NCPS project with interest or ideas (michael.houts@nasa.gov). 